identification of these subjects may slow the spread of SARS-CoV2. The cases of Veneto and Lombardia, contemporaneously affected neighboring regions in Italy, provide 2 telling examples with strikingly different endings. As of April 15, 2020, a total of 44,107 tests per million people have been performed in Veneto, which is double the number of tests conducted in Lombardia (Fig. 1). Indeed, in contrast to the neighboring region, Veneto adopted a large-scale population screening model at the beginning of the outbreak, allowing home isolation for a larger number of mild (or asymptomatic) cases ( $85 \%$ vs $60 \%$ of active cases according to the last estimates). ${ }^{4}$ This strategy may have avoided overwhelming the health system, with a consequent positive impact on the case fatality rate in Veneto, which is currently almost 3 times lower than that in Lombardia.

In fact, in line with previous modeling predictions, ${ }^{5}$ Lombardia did run out of intensive care beds at the end of March, resulting in the need to transfer critical patients to other Italian regions or European countries. Furthermore, between one-half and one-third of the daily national deaths are still being recorded in this region at this time.

At a time when Italy is facing its biggest challenge since World War II, the 'Veneto model' indicates that early mass screening for SARS-CoV-2 can make a positive difference, and it should be recommended to other countries responding to the COVID-19 pandemic.

Acknowledgments. None.

Financial support. No financial support was provided relevant to this article.

Conflicts of interest. All authors report no conflicts of interest relevant to this article.

\section{References}

1. Wu Z, McGoogan JM. Characteristics of and important lessons from the coronavirus disease 2019 (COVID-19) outbreak in China: summary of a report of 72,314 cases from the Chinese Center for Disease Control and Prevention. JAMA 2020;323:1239-1242.

2. Livingston E, Bucher K. Coronavirus disease 2019 (COVID-19) in Italy. JAMA 2020;323:1335.

3. Li R, Pei S, Chen B, et al. Substantial undocumented infection facilitates the rapid dissemination of novel coronavirus (SARS-CoV2). Science 2020;368: 489-493.

4. Coronavirus in Italia, i dati e la mappa [in Italian]. Lab 24 website. https:// lab24.ilsole24ore.com/coronavirus/. Accessed April 15, 2020.

5. Remuzzi A, Remuzzi G. COVID-19 and Italy: what next? Lancet 2020;395: 1225-1228.

\title{
Battle with COVID-19 in Iran: What lessons can be learned from the implementation of response strategies so far?
}

\author{
Mehrdad Amir-Behghadami MSc ${ }^{1,2,3}$ (10), Ali Janati $\mathrm{PhD}^{1,2}$ and Masoumeh Gholizadeh $\mathrm{PhD}^{1,2}$ \\ ${ }^{1}$ Tabriz Health Services Management Research Center, Health Management and Safety Promotion Research Institute, Tabriz University of Medical Sciences, \\ Tabriz, Iran, ${ }^{2}$ Iranian Center of Excellence in Health Management (IceHM), School of Management and Medical Informatics, Tabriz University of Medical Sciences, \\ Tabriz, Iran and ${ }^{3}$ Student Research Committee (SRC), Tabriz University of Medical Sciences, Tabriz, Iran
}

To the Editor-The novel coronavirus disease (COVID-19), with human-to-human transmission and severe human infection, has been escalating rapidly since late December $2019 .{ }^{1}$ Disease symptoms can range from mild flu-like cases to severe cases with life-threatening pneumonia., ${ }^{2,3}$ The global condition is evolving dynamically, and on January 30, 2020, the World Health Organization (WHO) announced that COVID-19 is a "public-health emergency of international concern." During the coronavirus pandemic, the authorities of the Iranian Ministry of Health and Medical Education (MOHME) reported the first cases of coronavirus on February 19, 2020 in Qom. ${ }^{4}$ As of March 6, 2020, according to MOHME, 27,017 cases of COVID-19 have been identified in the country, 2,077 of whom have died and 9,625 of whom have recovered so far. Following the widespread outbreak of SARS-CoV-2 in China, the MOHME launched a campaign in early February 2020 including

Author for correspondence: Mr. Mehrdad Amir-Behghadami, Iranian Center of Excellence in Health Management, School of Management and Medical Informatics, Tabriz University of Medical Sciences, University Rd, Golbad, EAZN 5165665811, Tabriz, East Azerbaijan, Iran. E-mail: Behghadami.m@gmail.com.

Cite this article: Amir-Behghadami M, Janati A, and Gholizadeh M. (2021). Battle with COVID-19 in Iran: What lessons can be learned from the implementation of response strategies so far?. Infection Control \& Hospital Epidemiology, 42: 237-239, https:// doi.org/10.1017/ice.2020.231 monitoring and examining all incoming travelers from China and quarantine of Iranian students residing in China.

Currently, no licensed vaccine for specific antiviral prevention and treatment is available for COVID $-19 .^{5}$ Therefore, the most effective measures are to eliminate the source of infection, to cut off the transmission route and to protect the susceptible. ${ }^{6}$ Prevention and control became the most urgent task in Iran during the early days of the sudden outbreak of the SARS-CoV-2 virus. ${ }^{7,8}$ In this regard, the government has invested large amounts of human capital and material resources. Regarding the origin of the infection, people who are in close contact with patients may become new patients or new sources of infection. For this reason, the first action after the media provided public education on COVID-19 disease was to establish a Corona National Antivirus Headquarters chaired by the President of Iran and headed by the MOHME. With the establishment of the headquarters, many actions were taken, such as canceling public events and Friday prayers; closing schools, universities, shopping centers and bazaars, as well as holy shrines; and banning festival celebrations. Economic measures were also taken to assist families and businesses. With the intersectoral collaboration, the headquarters is trying to control the outbreak of SARS-CoV-2. The Ministry of Roads and Urban Development initiated the necessary steps for public transport, and the Ministry of Industry, Mine, and Trade 


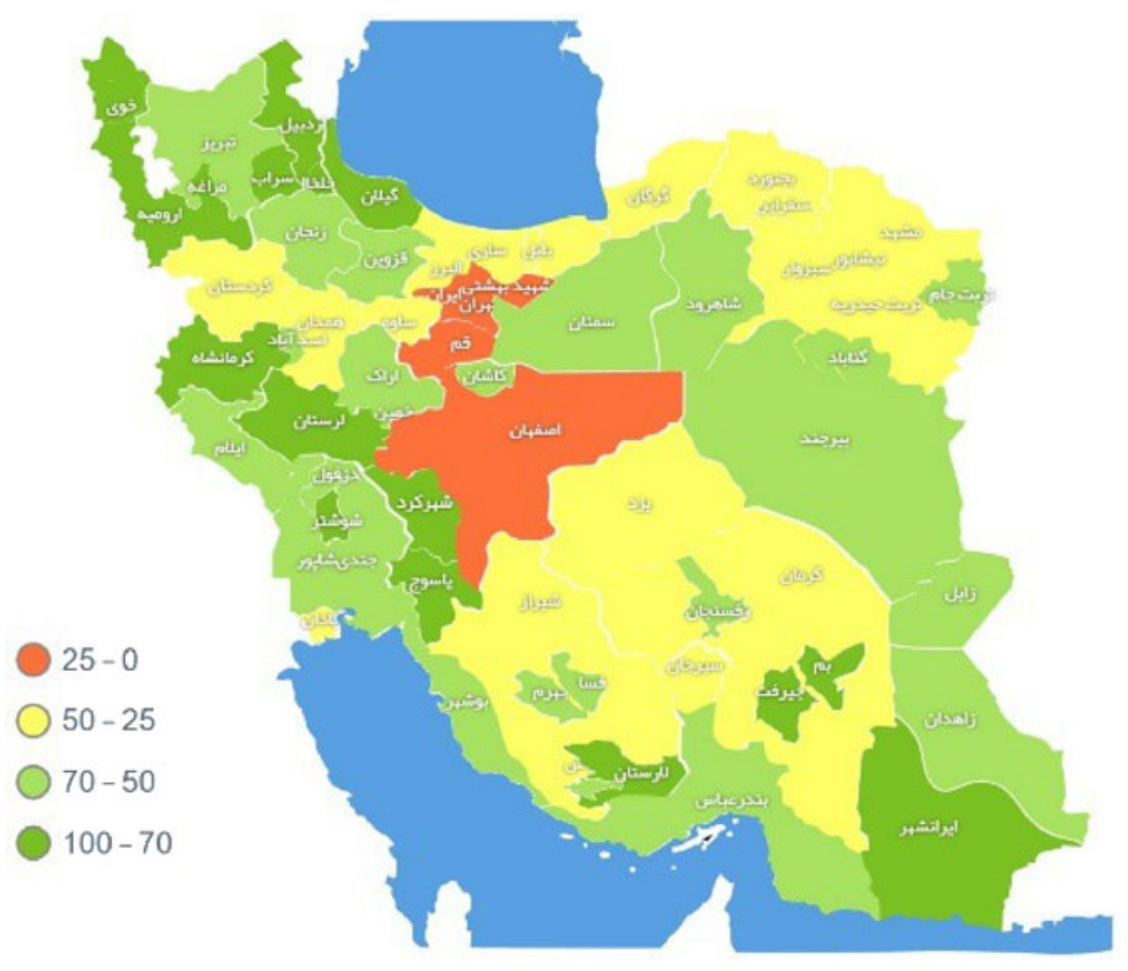

Fig. 1. Proportion of the target population screened for COVID-19 by province. Reference: Daily Situation Report on COVID-19, Ministry of Health and Medical Education, IR Iran.

will build the required medical equipment. On March 13, 2020, the Revolutionary Guard announced a plan to clear streets, shops, and public places in Iran. In addition, 1,000 fixed and mobile diagnostic clinics will be set up, and the military will work alongside medical providers as well as in the production of face masks and gloves, and army beds will be made available to patients. The Administrative and Employment Affairs Organization has allowed telecommuting of government employee and academic organizations. Academic organizations have also launched learning management systems.

The government created a mobile software application and a website to battle the COVID-19 epidemic. ${ }^{9}$ The COVID-19 SelfAssessment and Electronic Screening System was launched by MOHME on March 4, 2020 (salamat.gov.ir). When residents log into this system, they provide information such as national code, date of birth, and phone number, and they answer some questions about COVID-19 symptoms and their physical condition. After answering these questions, if a person is suspected of having a coronavirus, follow-up is provided through healthcare centers affiliated with the MOHME. The chart map shows proportion of the target population screened for COVID-19 by province (Fig. 1). People suspected of having COVID-19 receive a text message about their health status. If they do not recover physically after 3 days, they are referred to a hospital. Also, their homes will be disinfected, and other family members will be isolated if needed. The plan has been implemented, and thus far, with the allocation of $>17,000$ health houses and $>9,000$ comprehensive health centers in urban, suburban, and rural areas throughout the country. Organized epidemic response work has been carried out at these mobilization centers and bases.

The Social-Law Enforcement Committee of the Coronavirus Battle National Headquarters at the Iranian Interior Ministry began implementing the social distancing plan in March; it will continue through April 2020, and it will be extended by the Committee if necessary. According to the plan, intercity trips will be banned and only locals will be allowed to enter cities and towns.
Also, any sites that might draw large clusters of people, including schools, universities, shopping centers, parks, swimming pools, tourist sites, promenades, etc, will be closed. Holding any official or unofficial celebration that can draw crowds will also be forbidden during this period. Maximum restrictions will also be carried out regarding transport by aircraft, trains, and buses. There has been a significant effort to treat COVID-19 patients. $^{10}$ On March 26, 2020, Iran launched plasma therapy for coronainfected patients. ${ }^{11}$ The blood plasma of people who have recovered from COVID-19 infection will be donated to patients to boost their immune systems. Based on the concept of passive immunity, this new method will help improve the condition of patients. In the fight against SARS-CoV-2, it is crucial that countries around the world take steps to prevent transmission and save human lives. The Iranian authorities are implementing their policies and plans with the help of intersectoral collaboration and public participation. However, they should continue to develop new policies and programs to prevent and control the spread of SARS-CoV-2 until a vaccine or medication is available.

Acknowledgments. None.

Financial support. No financial support was provided relevant to this article.

Conflicts of interest. All authors report no conflicts of interest relevant to this article.

\section{References}

1. Zhu N, Zhang D, Wang W, et al. A novel coronavirus from patients with pneumonia in China, 2019. N Engl J Med. 2020;382:727-733.

2. Huang C, Wang Y, Li X, et al. Clinical features of patients infected with 2019 novel coronavirus in Wuhan, China. Lancet 2020;395:497-506.

3. Amir-Behghadami M, Gholizadeh M. Electronic screening through community engagement: A national strategic plan to find COVID-19 patients and reduce clinical intervention delays. Infect Control Hosp Epidemiol. 2020;1-2. doi: 10.1017/ice.2020.188. 
4. Farnoosh G, Alishiri G, Zijoud SRH, Dorostkar R, Farahani AJ. Understanding the 2019-novel coronavirus (2019-nCoV) and coronavirus disease (COVID-19) based on available evidence available evidencea narrative review. J Military Med 2020;22:1-11.

5. Din MAU, Boppana LKT. An update on the 2019-nCoV outbreak. Am J Infect Control 2020 Mar 11. pii: S0196-6553(20)30074-2. doi: 10.1016/j.ajic.2020.01.023.

6. Amiri P. The role of electronic health during the COVID-19 crisis: a systematic review of literature. J Health Biomed Informat 2020;6:358-367.

7. COVID-19 daily epidemiology journal [in Arabic]. Iranian Ministry of Health and Medical Education website. http://corona.behdasht.gov.ir/ files/site1/files/Journal_watch_6.pdf.pdf. Accessed March 28, 2020.

8. Amir-Behghadami M, Janati A. The importance of designing and implementing a participatory surveillance system: an approach to early detection and prevention of novel coronavirus (2019-nCov). Am J Infect Control 2020;6:731.

9. Amir-Behghadami M, Janati A. Iranian national COVID-19 electronic screening system: experience to share. Emerg Med J. Published Online First: 19 May 2020. doi: 10.1136/emermed-2020-209806.

10. Considerations relating to social distancing measures in response to COVID-19 — second update. European Centre for Disease Prevention and Control website. https://www.ecdc.europa.eu/sites/default/files/documents/covid-19-socialdistancing-measuresg-guide-second-update.pdf. Accessed March 28, 2020.

11. Iran to produce medicine for COVID-19 by plasma-derived therapy. Iran Press website. https://iranpress.com/en/iran-i144677-iran_to_produce_medicine_ for_covid_19_by_plasma_derived_therapy. Published March 7, 2020. Accessed May 12, 2020.

\title{
To relax restrictions: Are communities ready to deal with repeated epidemic waves of COVID-19?
}

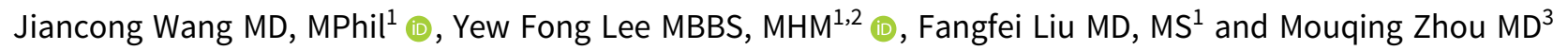 \\ ${ }^{1}$ Institute of Global Health, Faculty of Medicine, University of Geneva, Geneva, Switzerland, ${ }^{2}$ Ministry of Health, Kuala Lumpur, Malaysia and ${ }^{3}$ Dongguan \\ Nosocomial Infection Control and Quality Improvement Center, Dongguan City, Guangdong Province, China
}

To the Editor-With strict lockdown and movement restriction measures, in Europe the incidence of newly confirmed COVID-19 cases has slowed down and the epidemiological curve has flattened. ${ }^{1}$ However, the World Health Organization (WHO) has warned that the peak of the pandemic has not yet passed. ${ }^{2}$ However, some countries are considering relaxing restrictions because they have to weigh ethical issues and social and economic crises against another potential COVID-19 wave. ${ }^{3,4}$ When and how to relax the restrictions have become items of strong debate between health politicians and other stakeholders. According to the WHO's COVID-19 daily situation report and a recent study, ${ }^{5,6}$ community spread and clusters have predominantly contributed to most SARS-CoV-2 transmission. Therefore, the question facing policy makers remains: if restrictions are relaxed, will we be ready to deal with a repeated epidemic wave(s) in our community?

In China, resumption of works and production, reopening shops and restaurants, and even relaxation of travel restrictions have restored hope for virus-ravaged economies around the world. ${ }^{7}$ The National Health Commission of the People's Republic of China strengthened and implemented various measures and/or policies in the face of another potential epidemic wave. Here, we summarize the key elements of infection prevention and control (IPC) measures implemented in China.

First, border control included screening and testing for COVID-19. Imported cases from abroad, especially international travelers, pose a potential threat to the community if they are not properly screened at the borders. ${ }^{8}$ According to data retrieved on the April 18, 9 of every 16 newly confirmed cases (56\%) were identified as imported cases. ${ }^{9}$ Various measures (eg, travel history declaration, health epidemiological survey, temperature measurement, and rapid screening at airports) were conducted to efficiently

Author for correspondence: Jiancong Wang, E-mail: Jiancong.Wang@outlook.com Cite this article: Wang J, et al. (2021). To relax restrictions: Are communities ready to deal with repeated epidemic waves of COVID-19? Infection Control \& Hospital Epidemiology, 42: 239-240, https://doi.org/10.1017/ice.2020.228 detect suspected cases. All travelers were required to undergo a 14-day quarantine period at dedicated hotels, including SARSCoV-2 testing by swab. ${ }^{10}$ Detected cases were directly referred to dedicated COVID-19 hospitals, which minimized the risk to close contacts and the spread of disease in the community.

Second, informative technology and the Health Declaration mobile telephone software application (ie, app $)^{11}$ played a significant role in assessing the health status of residents. Information gathered was categorized and visualized using colored barcodes, which included each individual's national identification number and address, temperature results (if available), 14-day travel history declaration, and contact history with suspected or confirmed COVID-19 patients. A green barcode indicated that a person was at low risk of having COVID-19 and/or transmitting SARS-CoV-2 and had been given approval for a "health permit" that allowed to access workplaces, shops, and restaurants (Supplementary Material Fig. 1 online). A red barcode indicated that a person was at high risk of having COVID-19 and/or transmitting SARS-CoV-2 and that he or she would be contacted by the local health authorities for mandatory quarantine measures (by law) and medical observation.

Third, China implemented 'closed-off' management of residential communities. ${ }^{12}$ Only community residents were permitted enter or exit their residential areas, and no visitors were allowed. Temperature measurement was mandatory upon entry, and mask wearing was compulsory upon exiting a residential area. Even though mask use is still being debated in some countries, Asia, Austria, Germany, and the Czech Republic have demonstrated positive effects of using masks in reducing further spread of SARS-CoV-2 in the community. ${ }^{13}$

Fourth, community and public healthcare services were reinforced and supported. In Guangzhou, Sun Yat-Sen Memorial Hospital launched online consultation services by a dedicated professional COVID-19 team via the "internet community hospital" platform. ${ }^{14}$ This online service provided timely and accessible healthcare services and information to residents in the community, thus avoiding hospital

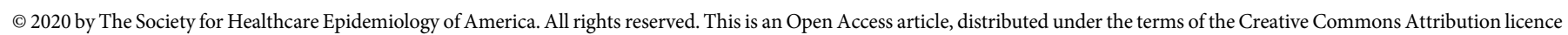
(http://creativecommons.org/licenses/by/4.0/), which permits unrestricted re-use, distribution, and reproduction in any medium, provided the original work is properly cited. 